\title{
EFFECT OF Fe, Ni AND Cr ON THE CORROSION BEHAVIOUR OF HYPEREUTECTIC AI-Si AUTOMOTIVE ALLOY IN 3.5\% NaCI SOLUTION AT DIFFERENT TEMPERATURE AND VELOCITY
}

\author{
M. S. Kaiser ${ }^{*}$, S. H. Sabbir ${ }^{2}$, M. Rahman², M. S. Kabir², M. Al Nur ${ }^{2}$ \\ ${ }^{1}$ Directorate of Advisory, Extension and Research Services \\ ${ }^{2}$ Department of Mechanical Engineering \\ Bangladesh University of Engineering and Technology, Dhaka-1000, Bangladesh \\ *Corresponding e-mail: mskaiser@iat.buet.ac.bd
}

\begin{abstract}
The main focus of this study is to examine and evaluate the effect of $\mathrm{Fe}, \mathrm{Ni}$ and $\mathrm{Cr}$ on the corrosion behaviour of hypereutectic Al-Si automotive alloy in 3.5\% $\mathrm{NaCl}$ solution. Experimental information are attained using conventional gravimetric measurements under different solution temperature and velocity and complemented by resistivity, optical micrograph, scanning electron microscopy (SEM) and X-ray analyzer (EDX) investigations. All the alloys show the negative corrosion rate due to formation of a very thin film of aluminum oxide and hydroxid on the surface. Intermetallic particles in the alloys play a major role in passivity. Temperature accelerates the corrosion and the higher velocity breakdown of the passive film. It also affects the resistivity of the alloys. The results from this study also indicate that the temperature and velocity increase the negative corrosion rate of the alloys due to higher rate of chemical reactions. SEM and EDX analysis indicate that the surfaces compose with a thin layer of aluminum oxide and hydroxide corrosion products.
\end{abstract}

Keywords: Al-Si alloys, Corrosion, $\mathrm{NaCl}$ solution, Heat, Velocity, SEM.

\section{INTRODUCTION}

The unique combinations of properties provided by aluminium and its alloys make aluminium one of the most versatile, economical, and attractive metallic materials for a broad range of uses - from soft, highly ductile wrapping foil to the most demanding engineering applications. Aluminium alloys are second only to steels in use as structural metals $[1,2]$. The increasing demand from many industries for improved properties in materials has stimulated the development of new materials. For the automotive industry, the properties most required are reduced weight, low thermal expansion coefficient, excellent mechanical properties, wear and corrosion resistance [3-5]. Iron is the most common impurity found in aluminium and is intentionally added to some pure alloys to provide a slight increase in strength [6,7]. Nickel is added to aluminium alloys to improve hardness and strength at elevated temperatures and to reduce the coefficient of expansion [8]. Chromium is added to aluminium to control grain structure, to prevent grain growth in aluminium-magnesium alloys, and to prevent recrystallization in aluminium-magnesium-silicon or aluminium-magnesium-zinc alloys during heat treatment. Chromium will also reduce stress corrosionAl susceptibility and improves toughness [9]. In general, concentration of alloying element and environmental condition play a great role on the corrosion behaviour of Al-alloys [10, 11]. A material faces decay due to corrosion as corrosion happens in normal temperature. Various measures are taken against corrosion to prevent materials from decaying.
But preventing corrosion is hard because there are various unknown factors working behind it.

The aim of the present study was to study the effects of $\mathrm{Fe}, \mathrm{Ni}$ and $\mathrm{Cr}$ on the corrosion behaviour of hypereutectic Al-Si automotive alloy in 3.5\% $\mathrm{NaCl}$ solution under different heat and velocity. The corroded surfaces of the alloys were examined after exposure using a scanning electron microscopy and electric conductivity meter to understand better the corrosion mechanisms.

\section{METHODS AND MATERIALS}

Melting was carried out in a resistance heating furnace under the suitable flux cover (degasser, borax etc.). First the aluminium engine block was melted in a clay-graphite crucible which was used as the master alloy. Four heats were taken for developing Al-Si base alloys. Alloy 1 was prepared directly from master alloy. Adding mild steel with master alloy which contains large amount of Fe in it, Alloy 2 was prepared. Alloy 3 was made by adding mild steel and $\mathrm{Ni}$ with master alloy which has considerable amount of $\mathrm{Fe}$ and $\mathrm{Ni}$ in it and Alloy 4 was produced by adding stainless steel with master alloy which contains $\mathrm{Fe}, \mathrm{Ni}$ and $\mathrm{Cr}$ in it. The final temperature of the melt was always maintained at $750 \pm 15^{\circ} \mathrm{C}$. Casting was done in cast iron metal moulds preheated to $200^{\circ} \mathrm{C}$. Mould sizes were $16 \times 150$ x 300 in millimetre. The alloys were analysed by wet chemical and petrochemical methods simultaneously. The chemical composition of the alloys is given in Table 1 . The cast alloys were homogenized at $400^{\circ} \mathrm{C}$ for 18 hours and air cooled to relieve internal stresses. The 
homogenized samples was solutionized at $530^{\circ} \mathrm{C}$ for 2 hours and then the samples were water quenched in salt ice water at a temperature below $20^{\circ} \mathrm{C}$ to obtain a super saturated single phase region. The homogenizing and solution treatment was conducted in an Electric Muffle furnace. The samples of $55 \times 15 \times 3 \mathrm{~mm}^{3}$ size obtained and were artificially aged at $175^{\circ} \mathrm{C}$ for 240 minutes to conduct the tests for studying the corrosion behaviour. The samples were wet-sanded mechanically with $\mathrm{SiC}$ papers of 220 and 1200 grit. Before use, the samples were de-greased with ethanol of $99 \%$ purity and then rinsed with plenty of water. Afterwards, they were dried, weighted (initial weight $\mathrm{W}_{\text {int }}$ ) different exposure periods up to 30 days. In this experiment a solution of $3.5 \% \mathrm{NaCl}$ at $\mathrm{pH} 5.5$ was used as medium for corrosion study. The solution was prepared by mixing $3.5 \pm 0.1$ parts of $\mathrm{NaCl}$ salt with $96.5 \pm 0.1$ parts of distilled water. Thus two solutions were prepared and one was kept at room temperature and other one was kept at $94^{\circ} \mathrm{C}$. Samples were rotated for 8 hours per day for 30 days in these solutions. After the exposer period the samples were rinsed with water and dried fully. Then they were weighted again for final measurement $\left(\mathrm{W}_{\text {fin }}\right)$. Weight loss was measured by using following equation [12].

$$
\begin{aligned}
& \text { Weight loss, } \Delta W=\frac{\left(W_{\text {int }}-W_{\text {fin }}\right)}{A} \\
& \text { Corrosion Rate, } K_{\text {Corr }}=\frac{(K \times \Delta W)}{(T \times D)} \\
& \text { Linear velocity, } \mathrm{V}=\frac{\operatorname{or} \times 2 \pi}{60}
\end{aligned}
$$

Where,

$$
\begin{aligned}
& \text { unit) } \\
& \mathrm{T}=\text { time of exposure }(\mathrm{hrs}) \\
& \mathrm{A}=\text { area in }\left(\mathrm{cm}^{2}\right) \\
& \Delta \mathrm{W}=\text { Weight loss }\left(\mathrm{mg} / \mathrm{cm}^{2}\right) \\
& \mathrm{D}=\text { density of metal }\left(\mathrm{g} / \mathrm{cm}^{3}\right) \\
& \mathrm{V}=\operatorname{Linear} \text { velocity }(\mathrm{m} / \mathrm{s}) \\
& \omega=\operatorname{angular} \text { speed }(\mathrm{rpm}) \\
& \mathrm{r}=\text { radius }(\mathrm{m})
\end{aligned}
$$$$
\mathrm{W}_{\text {int }}=\text { initial weight before immersion }(\mathrm{mg})
$$$$
\mathrm{W}_{\text {fin }}=\text { final weight after exposure }(\mathrm{mg})
$$$$
\mathrm{K}=\text { unit conversion constant }(\mathrm{K}=87.6 \text { for the mmpy }
$$

An Electric Conductivity Meter, type 979 was used to measure the electrical conductivity of the alloys at different conditions. Then the conductivity data were converted into Electric resistivity. The microstructural characterization of washed and dried samples has been carried out with the use of OPTIKA Microscope and JEOL scanning electron microscope with an energy dispersive X-ray analyzer (Model: Link AN - 10000). The SEM investigation and EDX analysis were obtained for the surface of the alloy specimens after their immersions in the solution medium for 30 days

Table1. Chemical composition of the experimental

\begin{tabular}{|c|c|c|c|c|}
\hline alloys (wt\%) \\
\hline ELEMENTS & Alloy 1 & Alloy 2 & Alloy 3 & Alloy 4 \\
\hline $\mathrm{Si}$ & 19.209 & 17.947 & 18.913 & 19.363 \\
\hline $\mathrm{Fe}$ & 0.795 & $\mathbf{5 . 9 1 0}$ & $\mathbf{6 . 2 5 6}$ & $\mathbf{5 . 5 0 1}$ \\
\hline $\mathrm{Ni}$ & 0.089 & 0.091 & $\mathbf{0 . 5 6 7}$ & $\mathbf{0 . 6 2 1}$ \\
\hline $\mathrm{Cr}$ & 0.040 & 0.086 & 0.057 & $\mathbf{1 . 2 6 7}$ \\
\hline $\mathrm{Cu}$ & 2.826 & 2.881 & 2.889 & 3.112 \\
\hline $\mathrm{Mg}$ & 0.245 & 0.186 & 0.193 & 0.232 \\
\hline $\mathrm{Zn}$ & 1.117 & 1.139 & 1.124 & 1.085 \\
\hline $\mathrm{Mn}$ & 0.214 & 0.183 & 0.178 & 0.217 \\
\hline $\mathrm{Ti}$ & 0.099 & 0.071 & 0.090 & 0.076 \\
\hline $\mathrm{Al}$ & $\mathrm{Bal}$ & $\mathrm{Bal}$ & $\mathrm{Bal}$ & $\mathrm{Bal}$ \\
\hline
\end{tabular}

\section{RESULTS AND DISCUSSIONS}

\section{Gravimetric analysis}

The weight loss $\Delta \mathrm{W}, \mathrm{mg} . \mathrm{cm}^{-2}$, calculated using Eq. (1) for the hypereutectic Al-19Si automotive Alloy 1, Fe added Alloy 2, Fe and Ni added Alloy 3 and Fe, Ni and $\mathrm{Cr}$ added Alloy 4 as a function of immersion time at room temperature and steady arrangement in 3.5\% $\mathrm{NaCl}$ solution is illustrated in Figure 1. It shows that all the alloys gain its weight with the immersion time. Under the velocity of $0.6 \mathrm{~m} / \mathrm{s}$ in same solution the weight gain increases (Figure 2). The weight loss graphs in Figure 3 and Figure 4, the same alloys under $94^{\circ} \mathrm{C}$ heated solution at steady arrangement and $0.6 \mathrm{~m} / \mathrm{s}$ velocity respectively show the similar results of weight gain. The reason behind this weight gain is the formation of passive films on top of the surface of the samples. This passive film acted like a barrier against corrosion so corrosion rate decreases. But corrosion is not omitted fully because of the gradual breakdown of passive films but still corrosion rate attains almost a constant value in this stage. For this reason the weight gain or negative weight loss decreases at a significant rate.

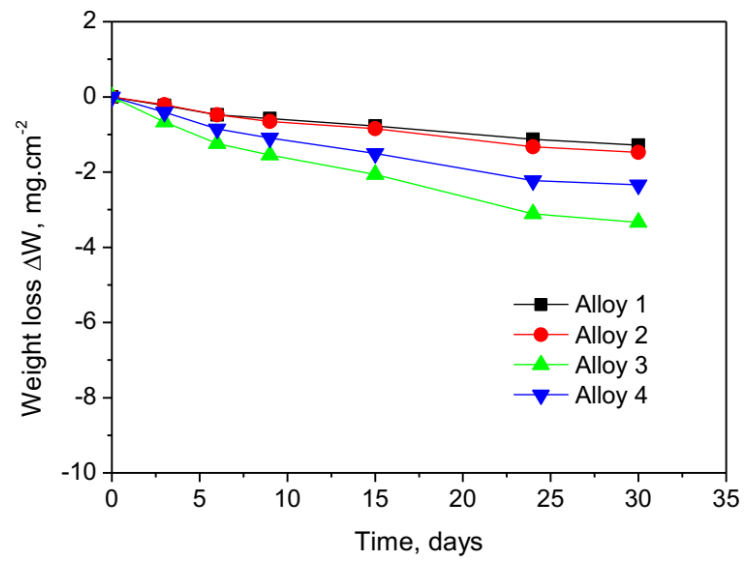

Figure 1. The variation of the weight loss as a function of immersion time of the experimental Al-Si automotive alloys under 0 velocity in $3.5 \% \mathrm{NaCl}$ solution at room temperature . 


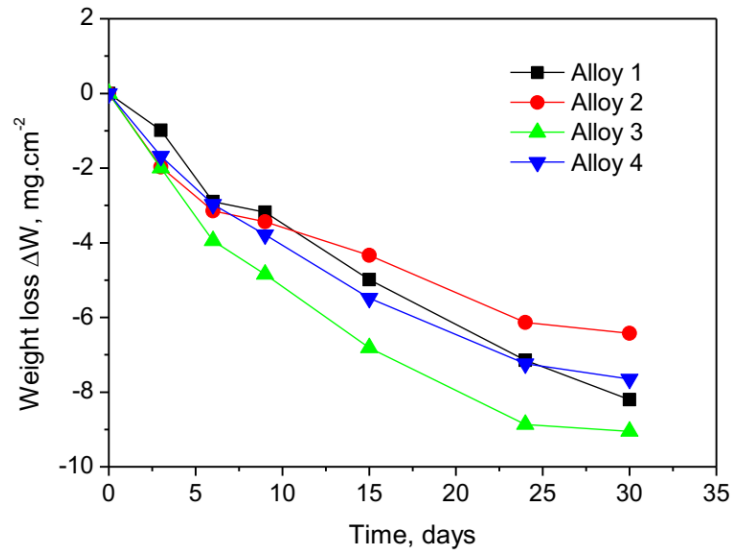

Figure 2. The variation of the weight loss as a function of immersion time of the experimental Al-Si automotive alloys under $0.6 \mathrm{~m} / \mathrm{s}$ velocity in $3.5 \% \mathrm{NaCl}$ solution at room temperature.

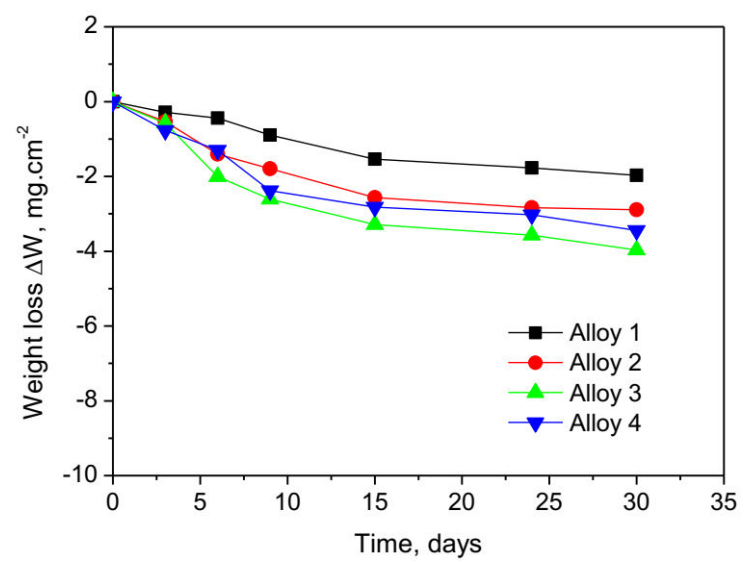

Figure 3. The variation of the weight loss as a function of immersion time of the experimental Al-Si automotive alloys under 0 velocity in $3.5 \% \mathrm{NaCl}$ solution heated at $94^{\circ} \mathrm{C}$.

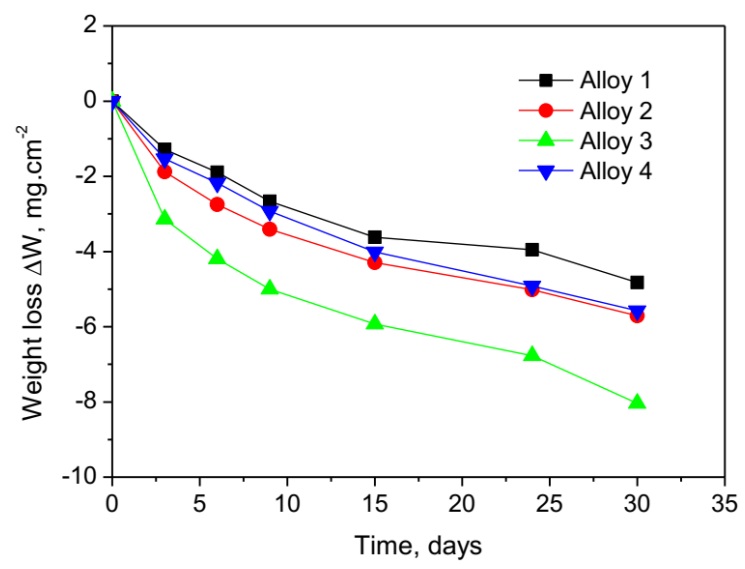

Figure 4. The variation of the weight loss as a function of immersion time of the experimental Al-Si automotive alloys under $0.6 \mathrm{~m} / \mathrm{s}$ velocity in $3.5 \% \mathrm{NaCl}$ solution heated at $94^{\circ} \mathrm{C}$.
The relative corrosion rate $\mathrm{K}_{\text {corr, }}$, was calculated using Eq. (2) for the experimental alloys. Graphs of corrosion rate were plotted against immersion time at room temperature and $94^{\circ} \mathrm{C}$ temperature for all the alloys with no velocity and with $0.6 \mathrm{~m} / \mathrm{s}$ velocity. These are presented in Figures 5-8. From the graphs, the negetive corrosion rate profile is observed against time in the experimental solution. All the samples shows an increased corrosion rate within the first 3 days of the experiment but as the time exposer gets higher the corrosion rate decreases at a significant rate. It is mainly because at the first stage of the experiment the metal surface was exposed inside the solution so the ion adsorption on the surface was high. Various oxide and hydroxide layer formed on top of it. In comparative terms, Alloy 3 showed the highest negative values of corrosion penetration rate in virtually all the media concentration; especially in heated solution. It may be because Alloy 3 contains nickel which has a better rate of ion adsorption. Figures show that the corrosion rate was almost uniform at later stage. Since the process of corrosion is electrochemical in nature, increasing the temperature usually also increases the rate of corrosion. This is because heat a substance, the particles move quicker and so collide more frequently [13]. Consequently the rate of corrosion speeds up in hotter environments, and slows down in cooler ones. The basic mechanism is that the addition of alloying elements $\mathrm{Cr}$, results in the formation of protective passive films on the surface, which prevents further corrosion of the alloys underneath [14].

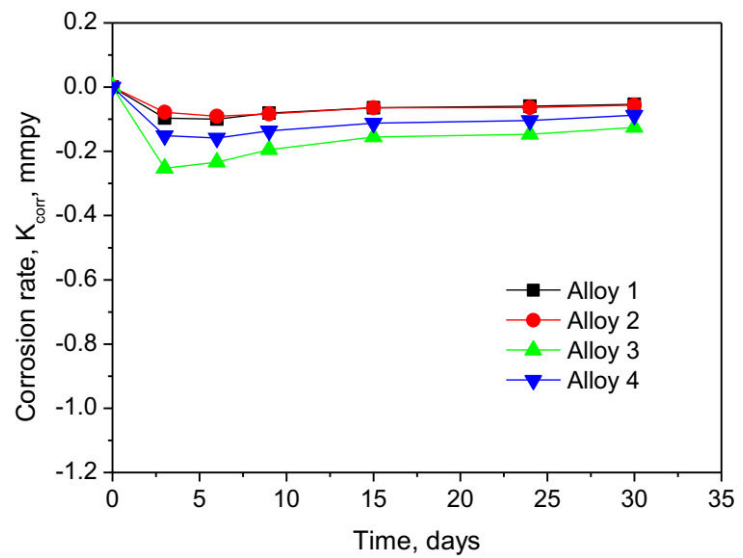

Figure 5. The variation of corrosion rate as a function of immersion time for the experimental $\mathrm{Al}-\mathrm{Si}$ automotive alloys under 0 velocity in $3.5 \% \mathrm{NaCl}$ solution at room temperature . 


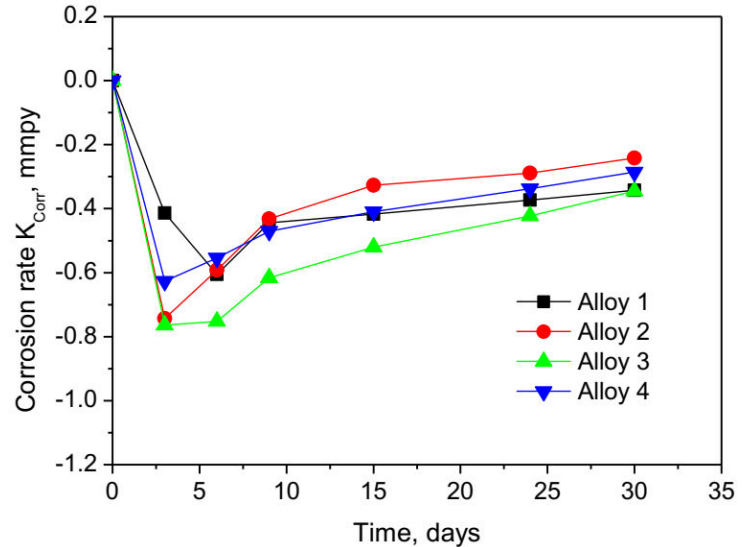

Figure 6. The variation of corrosion rate as a function of immersion time for the experimental Al-Si automotive alloys under $0.6 \mathrm{~m} / \mathrm{s}$ velocity in $3.5 \% \mathrm{NaCl}$ solution at room temperature.

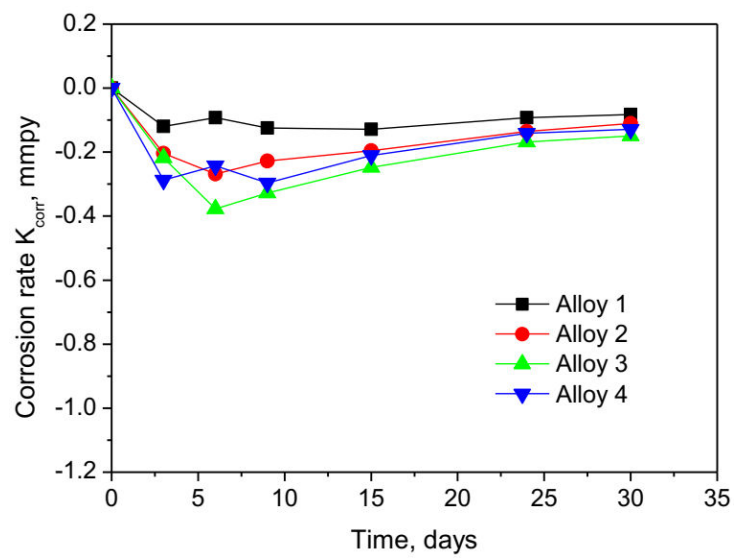

Figure 7. The variation of corrosion rate as a function of immersion time for the experimental Al-Si automotive alloys under 0 velocity in $3.5 \% \mathrm{NaCl}$ solution heated at $94^{\circ} \mathrm{C}$.

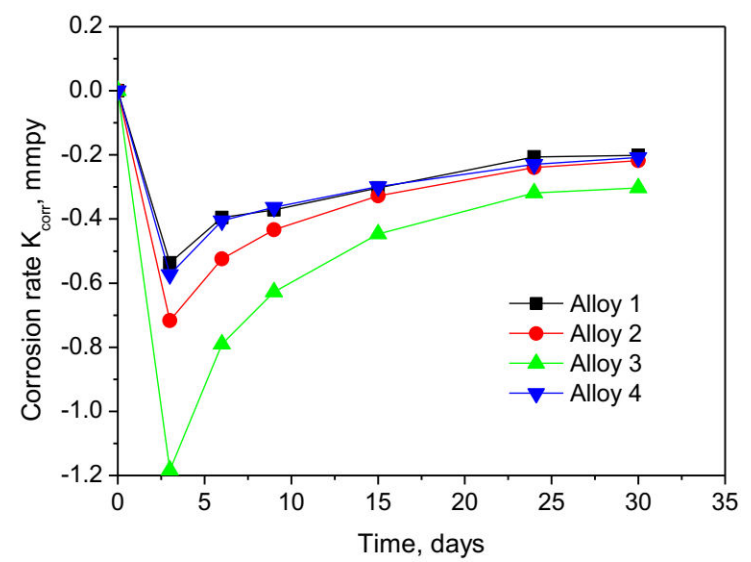

Figure 8 . The variation of corrosion rate as a function of immersion time for the experimental Al-Si automotive alloys under $0.6 \mathrm{~m} / \mathrm{s}$ velocity in $3.5 \% \mathrm{NaCl}$ solution heated at $94^{\circ} \mathrm{C}$.

\section{Resistivity analysis}

Figure 9 and Figure 10 show the resistivity values of the alloys immersed in $3.5 \% \mathrm{NaCl}$ solution at $94^{\circ} \mathrm{C}$ temperature for 30 days under steady condition and $0.6 \mathrm{~m} / \mathrm{s}$ velocity respectively. It shows a general trend of decrease. This is due to the fact that aluminum forms a very thin film of aluminum oxide and hydroxide and it has a bond to its surface which affects the resistivity. The formation of oxide film on top of the surface seems to increase the conductivity of the alloys in other word decrease the resistivity. In case of the moving heated solution the resistivity of the alloys increases slightly after prolong immersion time. It is due to fact that the increasing temperature accelerates the reaction rate which increases the corrosion rate of the alloys. Gradual breakdown of the passive films also occurs at higher velocity [11]. So higher pit formation produces an uneven surface which increases the electrical resistivity of the surface of the experimental alloys. The initial resistivities of the alloys are different because of the different elements present in the alloys. Alloy 1 shows the minimum rate of decreasing in resistivity due to minimum weight gain and Alloy 3 shows the highest decreasing in resistivity due to highest weight gain during corrosion.

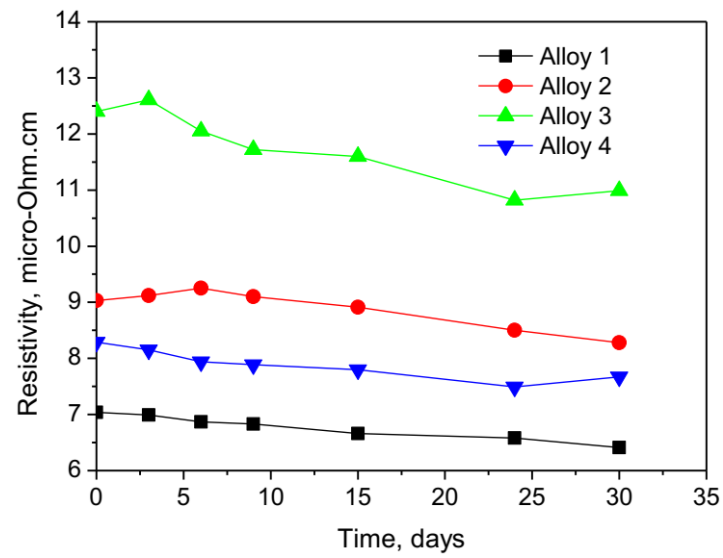

Figure 9. The change of resistivity as a function of immersion time for the experimental Al-Si automotive alloys at 0 velocity in $3.5 \% \mathrm{NaCl}$ solution heated at $94^{\circ} \mathrm{C}$. 


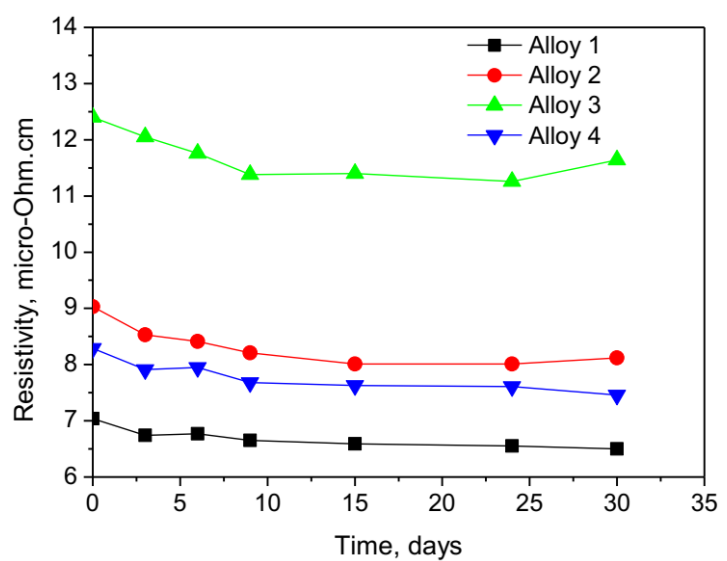

Figure 10. The change of resistivity as a function of immersion time for the experimental Al-Si automotive alloys at $0.6 \mathrm{~m} / \mathrm{s}$ velocity in $3.5 \% \mathrm{NaCl}$ solution heated at $94^{\circ} \mathrm{C}$.

\section{Optical micrographic observation}

Figure 11 shows the optical micrograph of polished Al-19Si automotive Alloy 1, Fe added Alloy 2, Fe and $\mathrm{Ni}$ added Alloy 3 and $\mathrm{Fe}, \mathrm{Ni}$ and $\mathrm{Cr}$ added Alloy 4 before immersion into the corrosion medium and after corrosion in room temperature and $94^{\circ} \mathrm{C}$ for 30 days. The samples have a microstructure characterized by an Al-rich dendritic matrix, $\alpha$-Al phase and a eutectic mixture in the interdendritic state formed by silicon particles. In this type of image the precipitates of $\mathrm{Al}(\mathrm{Mn}, \mathrm{Fe}, \mathrm{Cu})$ are those that come into view in the dark tone while those of $\mathrm{Al}(\mathrm{Si}, \mathrm{Mg})$ become visible in a
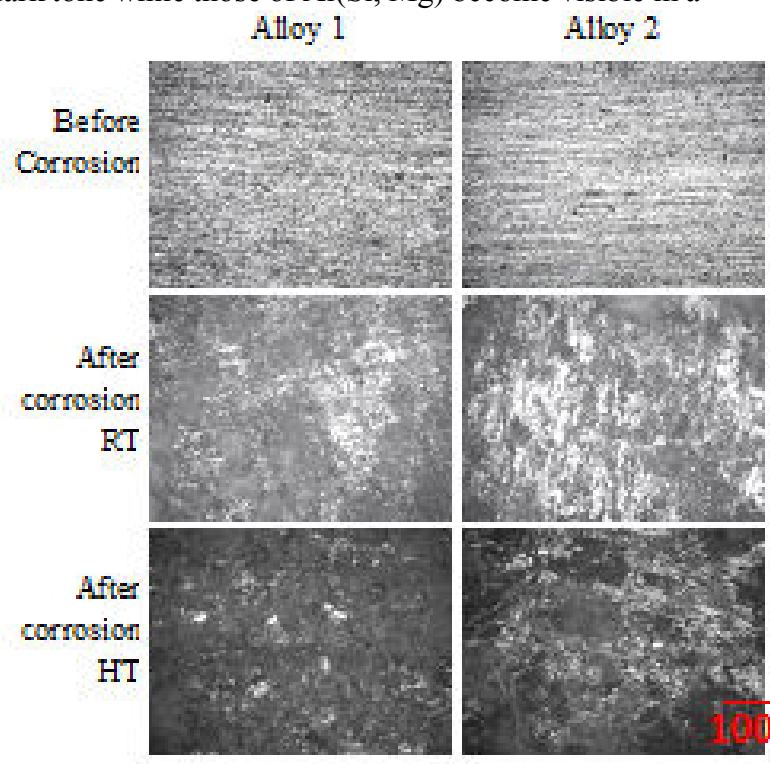

Samples immersed in hot solution faced intense corrosion. The reason behind it is in hot environment most chemical reaction rate goes higher because of the movement of molecules which increases their energy to complete the reaction. So the increases temperature acted as a booster for corrosion reaction [15]. In both conditions room temperature and heated solution, microstructure in Alloy 3 is much higher than the other alloys. It may be due to the intermetallic bond between $\mathrm{Ni}$ and Al-Si alloy has a strong oxide attraction which increases the corrosion.

\section{SEM and EDX observation}

Generally the microstructures of Al-Si automotive alloy may be characterized by $\alpha-\mathrm{Al}$ matrix, eutectic $\mathrm{Si}$ and different intermetallic phases on $\alpha$-Al matrix in the inter-dendritic region [15]. The SEM images of the hypereutectic Al-19Si automotive alloys after exposure in $94^{\circ} \mathrm{C}$ heated $3.5 \% \mathrm{NaCl}$ solution for 30 days with a velocity of $0.6 \mathrm{~m} / \mathrm{s}$ are shown in Figure 12 . The surface of the alloys creates of mushrooms type corrosion layer and the other area is covered with a thin layer of corrosion products [16]. Some pits are observed on the surface due to break down the passive film. It is more prominent in case of Alloy 3 because of the higher rate of corrosion and higher the breakdown of passive film at higher velocity. The weight percentage of elements found by EDX analysis in the selected area of the SEM are $33.03 \% \mathrm{O}, 4.60 \% \mathrm{Na}, 5.12 \% \mathrm{Mg}, 24.11 \% \mathrm{Al}$, $28.82 \% \mathrm{Si}, 0.49 \% \mathrm{Cl}, 0.33 \% \mathrm{Ti}, 0.04 \% \mathrm{Cr}, 0.19 \% \mathrm{Mn}$, $2.19 \% \mathrm{Fe}, 0.40 \% \mathrm{Ni}, 0.09 \% \mathrm{Cu}$ and $0.59 \% \mathrm{Zn}$ for the

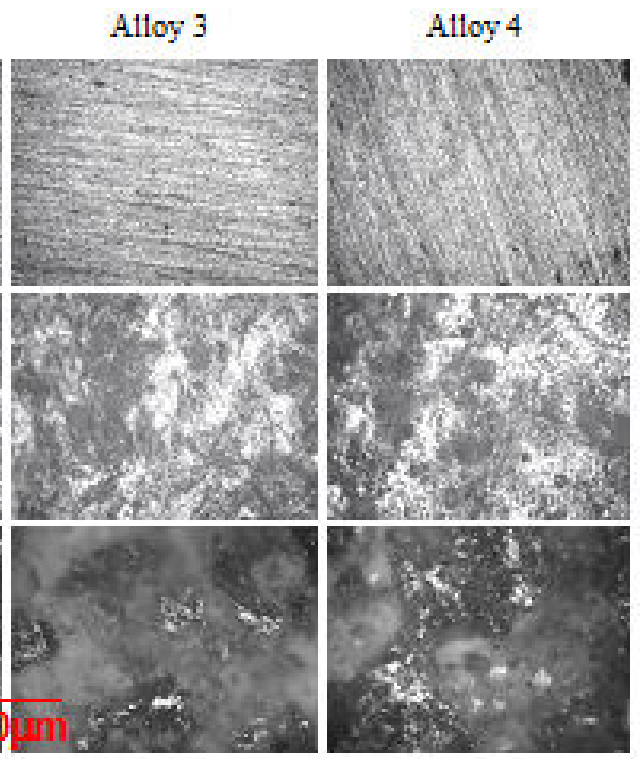

Figure 11. Microstructure of hypereutectic Al-Si automotive alloys before corrosion, after corrosion with a velocity of $0.6 \mathrm{~m} / \mathrm{s}$ in $3.5 \% \mathrm{NaCl}$ solution at room temperature and after $94^{\circ} \mathrm{C}$ heated $3.5 \% \mathrm{NaCl}$ solution for 30 days

lighter tone. It is also seen from the figure that after removing the samples from the room temperature solution for 30 days, severe corrosion was observed.
Alloy 1 (Fig. 12 a). The weight percentage of elements of Alloy 2 found by EDX analysis in the selected area of the SEM for the alloy at higher temperature solution 

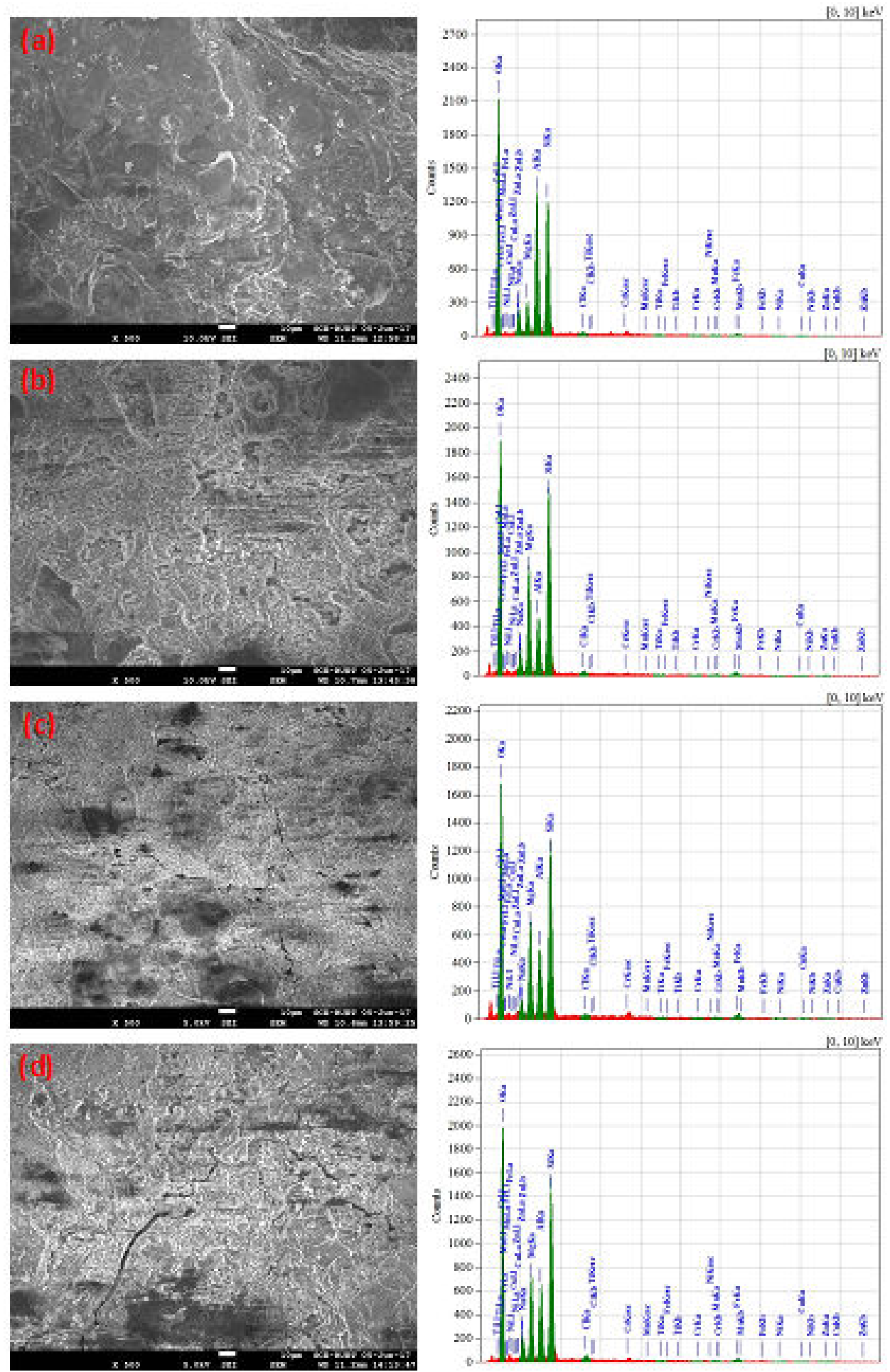

Figure 12. SEM images after exposure in $94^{\circ} \mathrm{C}$ heated $3.5 \% \mathrm{NaCl}$ solution for 30 days with a velocity of $0.6 \mathrm{~m} / \mathrm{s}$ (a) Alloy 1 (b) Alloy 2, (b) Alloy 3 and (d) Alloy 4. 
are $28.90 \% \mathrm{O}, 3.67 \% \mathrm{Na}, 16.31 \% \mathrm{Mg}, 9.14 \% \mathrm{Al}$, $32.96 \% \mathrm{Si}, 0.73 \% \mathrm{Cl}, 0.90 \% \mathrm{Mn}, 3.42 \% \mathrm{Fe}, 0.12 \%$ $\mathrm{Ni}, 0.94 \% \mathrm{Cu}$ and $2.91 \% \mathrm{Zn}$ (Fig. $12 \mathrm{~b}$ ). In case of Alloy 3 the weight percentage of elements are $29.54 \% \mathrm{O}$, $2.37 \% \mathrm{Na}, 14.67 \% \mathrm{Mg}, 11.50 \% \mathrm{Al}, 31.91 \% \mathrm{Si}, 0.41 \%$ $\mathrm{Cl}, 0.08 \% \mathrm{Ti}, 1.10 \% \mathrm{Mn}, 5.12 \% \mathrm{Fe}, 1.71 \% \mathrm{Cu}$ and $1.45 \% \mathrm{Zn}$ (Fig. 12 c). Alloy 4 shows the weight percentage of elements $31.65 \% \mathrm{O}, 3.65 \% \mathrm{Na}, 13.16 \%$ $\mathrm{Mg}, 12.41 \% \mathrm{Al}, 33.17 \% \mathrm{Si}, 1.05 \% \mathrm{Cl}, 0.13 \% \mathrm{Ti}$, $0.35 \% \mathrm{Cr}, 0.52 \% \mathrm{Mn}, 3.76 \% \mathrm{Fe}$, and $0.15 \% \mathrm{Cu}$ (Fig. $12 \mathrm{~d}$ ). Additionally, the presence of high percentage of oxygen and low concentration of Fe in the alloy after immersion clearly indicate the formation of an oxide layer or film on its outer surface.

\section{CONCLUSIONS}

Presences of $\mathrm{Fe}, \mathrm{Ni}$ and $\mathrm{Cr}$ in hypereutectic $\mathrm{Al}-\mathrm{Si}$ automotive alloy under different temperature and velocity have an effect on the corrosion behaviour of the alloy. From the results obtained it can be concluded that all the alloys show the negative corrosion rate due to formation of a very thin film of aluminum oxide and hydroxide on the surface. The temperature acts as a catalyst for higher rate of chemical reactions which increase the corrosion of the alloys. Gradual breakdown of the passive films take place at higher velocity. But with increase of time exposer it tends to gain a steady state value because the rate of breaking down of passive film and formation of oxide almost equals. Intermetallic particles in the alloys played a major role in passivity breakdown. The formation of the thin film decrees the resistivity of the alloys due to the formation of conductive film on top of the surface. The corroded surface shows that the surface is completely corroded, which confirms the aggressive action of the $\mathrm{NaCl}$ on the alloys.

\section{ACKNOWLEDGEMENTS}

This work is supported by the Department of Mechanical Engineering of Bangladesh University of Engineering and Technology. Thanks to Department of Glass and Ceramics Engineering for providing the laboratory facilities.

\section{REFERENCES}

1. J.R. Davis, 1998, "Introduction to Aluminum and Aluminum Alloys", 2nd Edition, ASM International, $\mathrm{OH}$, USA.

2. I.J. Polmear, 1995, "Light Alloys. Metallurgy of the Light Metals", 3rd Edition, Butterworth-Heinemann, UK.

3. M.S. Kaiser, M.R. Basher and A.S.W. Kurny, 2012, "Effect of scandium on microstructure and mechanical properties of cast Al-Si-Mg alloy", Journal of Materials Engineering and Performance, Vol. 21, No. 7, pp. 1504-1508.

4. H.O Santos, F.M. Reis, C.T. Kunioshi, J.L. Rossi and I. Costa, 2005, "Corrosion performance of
Al-Si-Cu hypereutectic alloys in a synthetic condensed automotive solution", Materials Research, Vol. 8, No. 2, pp. 155-159.

5. M.S. Kaiser, 2016, "Effects of solution treatment on wear behaviour of Al-12Si-1 Mg piston alloy containing trace Zr", MAYFEB Journal of Materials Science, Vol. 1, pp. 27-38.

6. R.S. Rana, R. Purohit and S Das, 2012, "Reviews on the influences of alloying elements on the microstructure and mechanical properties of aluminum alloys and aluminum alloy composites", International Journal of Scientific and Research Publications, Vol. 2, No. 6, pp. 1-7.

7. T.O. Mbuya, B.O. Odera and S.P. Nganga, 2003, "Influence of iron on castability and properties of aluminium silicon alloys: literature review", International Journal of Cast Metals Research, Vol. 6, No. 5, pp. 451-465.

8. C.Y. Jeong, 2012, "Effect of alloying elements on high temperature mechanical properties for piston alloy", Materials Transactions, Vol. 53, No. 1, pp. 234-239.

9. A.K. Mukhopadhyay, 2009, "Microstructure and properties of high strength aluminium alloys for structural applications", Transactions of the Indian Institute of Metals, Vol. 62, No. 2, pp. 113-122.

10. A.H. Seikh, M. Baig, H.R. Ammar and M.A. Alam, 2016, "The influence of transition metals addition on the corrosion resistance of nanocrystalline Al alloys produced by mechanical alloying", Metals, Vol. 6. No. 6, pp. 1-14.

11. M.S. Kaiser, 2017, "Effect of temperature on the corrosion behaviour of Al-12Si-1Mg automotive alloy in $3.5 \% \mathrm{NaCl}$ solution", International Journal of Materials Science and Engineering, Vol. 5, No. 2, pp. 87-94.

12. A. Philip and P.E. Schweitzer, 2004, "Encyclopedia Corrosion Technology", 2nd Edition, Marcel Dekker Inc., New York, USA.

13. A. Clarke, 2006, "Temperature and the metabolic theory of ecology", Functional Ecology, Vol. 20, pp. 405-412.

14. Y.Y. Chen, T. Duval, U.D. Hung, J.W. Yeh and H.C. Shih, 2005, "Microstructure and electrochemical properties of high entropy alloys - a comparison with type-304 stainless steel”, Corrosion Science, Vol. 47, No. 9, pp. 2257-2279.

15. R. Arrabal, B. Mingo, A. Pardo, M. Mohedano, E. Matykina, M.C. Merino and A. Rivas, 2015, "Microstructure and corrosion behaviour of A356 aluminium alloy modified with $\mathrm{Nd}$ ", Materials and Corrosion, Vol. 66, No. 6, pp. 535-541.

16. H.R. Copson, 1952, "Effects of velocity on corrosion by water", Industrial and Engineering Chemistry, Vol. 44, No. 8, pp. 1745-1752. 